\title{
Primary Prostatic Lymphoma of Mucosa-Associated Lymphoid Tissue
}

\author{
Saori Tomikawa, Hirokazu Okumura, Takashi Yoshida, Hiroyasu Mochizuki, \\ Atsuo Mrwa*, Koretatsu TaKayanagi**, Tadashi Yoshino***, Shigeki OHTaKe****, \\ Masaki FujImURA $* * * *$, Shinobu NAKAMURA $* * * *$ and Tamotsu MATSUdA $* * * *$
}

\begin{abstract}
We present a case of primary prostatic lymphoma referring to a 57-year-old man, who was admitted with the symptom of bladder outlet obstruction, and had a history of urination difficulty for two years. The symptoms and signs were compatible with a diagnosis of benign prostatic hypertrophy (BPH). The pathology of the specimen obtained from transurethral prostatectomy showed B-cell lymphoma of mucosa-associated lymphoid tissue (MALT) type. The patient has been asymptomatic and under complete remission after completion of chemotherapy consisting of doxorubicin, cyclophosphamide, vincristine and prednisone for 6 cycles.

(Internal Medicine 37: 628-630, 1998)
\end{abstract}

Key words: B-cell lymphoma, mucosa-associated lymphoid tissue (MALT), prostate, prostatic hypertrophy

\section{Introduction}

Low-grade lymphoma of the mucosa-associated lymphoid tissue (MALT) type is now included in the Revised EuropeanAmerican Classification of Lymphoid Neoplasms (REAL Classification) (1). Two-thirds of MALT lymphomas are derived from the stomach (2), and many of patients have helicobacter pylori gastritis $(3,4)$. On the other hand, primary prostatic lymphoma is a rare malignancy and it is estimated that less than 100 cases have been reported in the world literature $(5,6)$. We report here a case of primary prostatic lymphoma of MALT type who had the history of prostatic hypertrophy. This suggests the etiology of primary prostatic lymphoma of MALT type.

\section{Case Report}

A 57-year-old man presented with the progressing symptom of bladder outlet obstruction. He had noted dysuria, nocturia, and sensation of residual urine for two years. The physical examination was unremarkable except for a firm, moderately enlarged prostate with tenderness and no lymphadenopathy. There was no abnormal laboratory data. Retrograde urethrogram and computed tomography (CT) scan suggested benign prostatic hypertrophy (BPH). Transurethral resection of the prostate was performed. Histological examination of the prostatic gland revealed many hyperplastic glands and infiltration with lymphocytes and plasma cells around the acini (Fig. 1). Moreover, there were centrocyte-like (CCL) cells, lymphatic follicles, and lymphoepithelial lesions (Fig. 2A, B). These are the features of lymphoma arising from the MALT. Immunohistochemical analysis classified it as a B-cell phenotype with selective reactivity for CD 20 antigen (Fig. 2C), and it did not express MT 1 antigen. The pathological diagnosis made was Bcell lymphoma of MALT type. Complete clinical investigation, including bone marrow biopsy, did not show any other involved site. The patient received 6 cycles of chemotherapy consisting of cyclophosphamide, doxorubicin, vincristine, and prednisone (CHOP). The patient has kept complete remission for 18 months after diagnosis.

\section{Discussion}

Primary prostatic lymphoma is a rare malignancy. The frequency is reported as $0.1 \%$ of non-Hodgkin's lymphomas, and $0.09 \%$ of prostatic neoplasms (5). We diagnosed this MALT lymphoma by morphologic features. If we studied the

From the Department of Internal Medicine, and *the Department of Pathology, Toyama Prefectural Central Hospital, Toyama, **Health Control Center, Toyama City Medical Association, Toyama, ***the Second Department of Pathology, Okayama University School of Medicine, Okayama and ****the Third Department of Internal Medicine, Kanazawa University School of Medicine, Kanazawa

Received for publication September 5, 1997; Accepted for publication March 3, 1998

Reprint requests should be addressed to Dr. Saori Tomikawa, the Third Department of Internal Medicine, Kanazawa University, 13-1 Takara-machi, Kanazawa 920-8641 
immunohistologic and genetic features, it could be distinguished from other low grade lymphomas more certainly.

Generally, MALT lymphoma patients have a long survival, and high response rate with local treatment (surgery or radio-

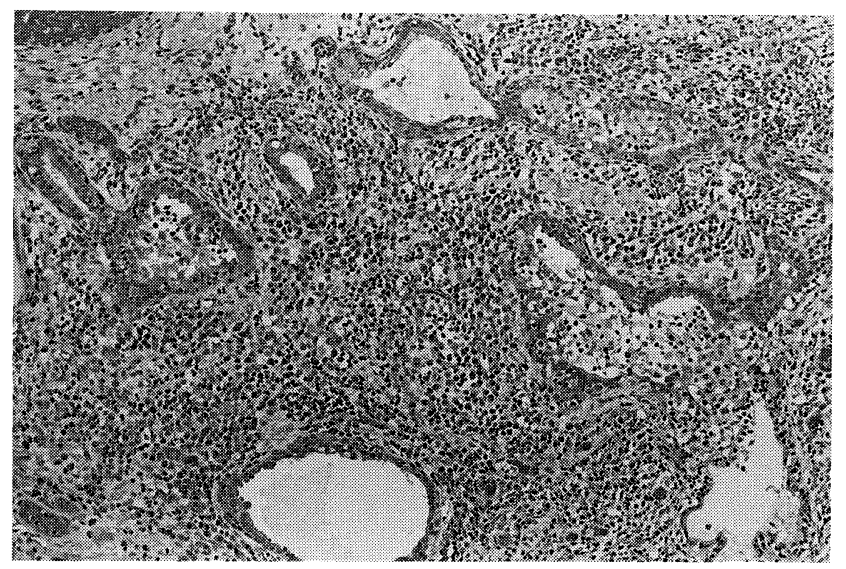

Figure 1. Hyperplastic glands and infiltration with lymphocytes and plasma cells around the acini of the prostate (HE stain, $\times \mathbf{2 0}$ ).
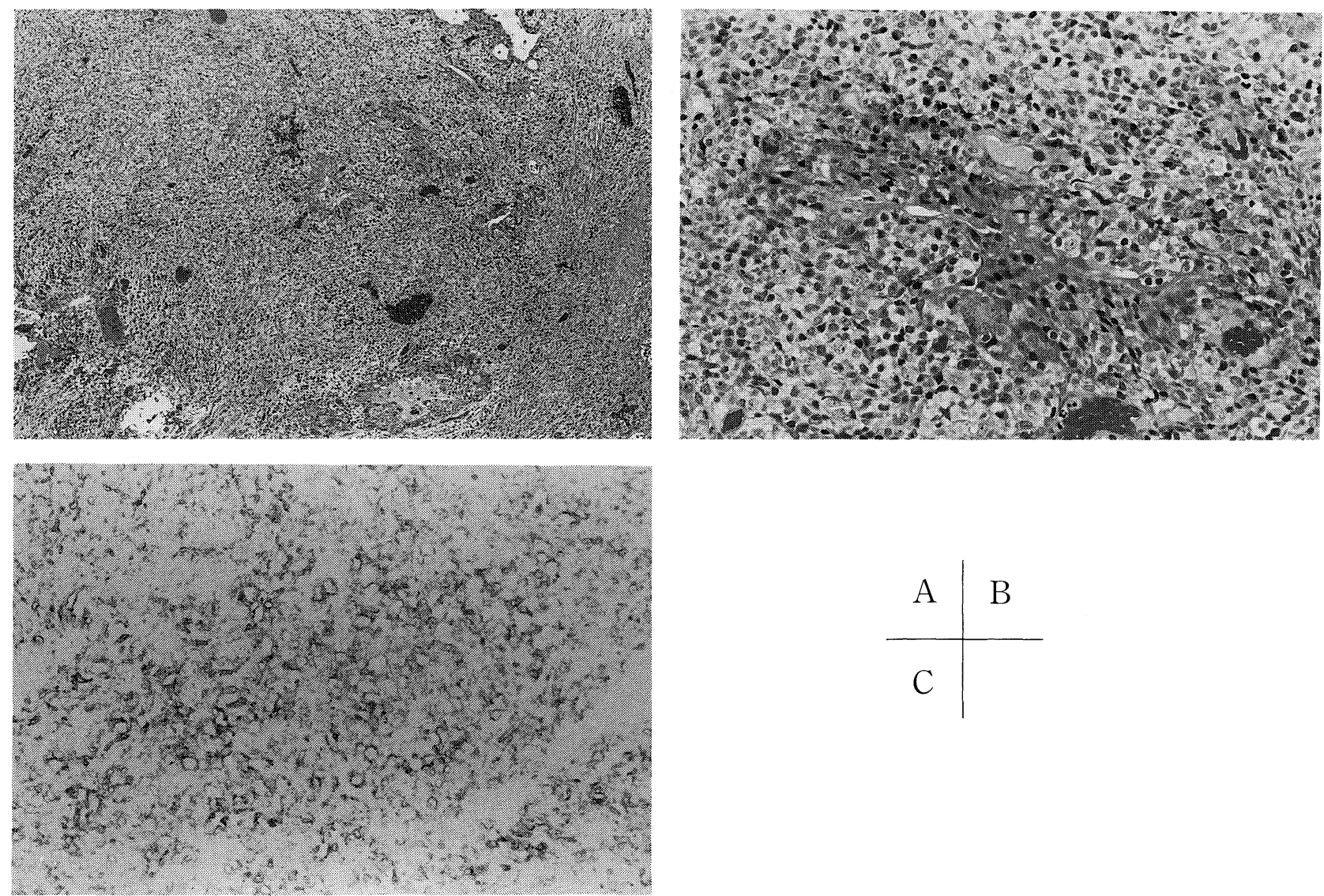

therapy) (2). In this case, prostatic lymphoma was resected by means of transurethral resection, thus there was a possibility of remaining of lymphoma cells at the prostate. For this reason, we gave 6 cycles of CHOP.

Most MALT lymphomas are detected in the stomach, but they may also be observed in the breast, bladder, conjunctiva, kidney, liver, lung, skin, salivary glands, thyroid, and thymus (2). Many patients have a history of chronic inflammatory disorders or autoimmune disease, such as chronic gastritis (helicobacterpylori gastritis), Sjögren's syndrome, Hashimoto's thyroiditis, and interstitial lymphoid pneumonia $(1,2)$. This suggests that autoimmune disease or chronic inflammatory disorders may form the substrate for the development of lymphoma $(1,2,4)$.

The present patient had noted dysuria and nocturia for two years that can be considered as symptoms of BPH. In the specimen, there were many hyperplastic glands, as well as infiltration with lymphocytes and plasma cells around the acini, supporting the presence of chronic inflammation in the prostatic glands. In this case, we consider that prostatic MALT was acquired in BPH with prostatitis, which provided the necessary background for MALT lymphoma to develop.

Figure 2. Pathological specimen of the prostate showing lymphatic follicles, CCL cells, lymphoepithelial lesions: (A) (HE stain, $\times 20)$, (B) (HE stain, $\times 80)$. (C) The lymphoma cells express CD 20 antigen $(\times 100)$. 


\section{Tomikawa et al}

\section{References}

1) Harris NL, Jaffe ES, Stein H, et al. A revised European-American classification of lymphoid neoplasms: a proposal from the International Lymphoma Study Group. Blood 84: 1361, 1994.

2) Thieblemont C, Berger F, Coiffier B. Mucosa-associated lymphoid tissue lymphomas. Curr Opin Oncol 7: 415, 1995.

3) Wyatt JI, Rathbone BJ. Immune response of the gastric mucosa to
Campylobacter pylori. Scand J Gastroenterol Suppl 142: 44, 1988.

4) Wotherspoon AC, Ortiz-Hidalgo C,Falzon MR, Isaacson PG. Helicobacter pylori-associated gastritis and primary B-cell gastric lymphoma. Lancet 338: 1175, 1991.

5) Sarris A, Dimopoulos M, Pugh W, Cabanillas F. Primary lymphoma of the prostate: Good outcome with doxorubicin-based combination chemotherapy. J Urol 153: 1852, 1995.

6) Fell P, O'Connor M, Smith JM. Primary lymphoma of prostate presenting as bladder outflow obstruction. Urology 29: 555, 1987. 